\title{
Strong Resistance Against Rice grassy stunt virus Is Induced in Transgenic Rice Plants Expressing Double-Stranded RNA of the Viral Genes for Nucleocapsid or Movement Proteins as Targets for RNA Interference
}

\author{
Takumi Shimizu, Takumi Ogamino, Akihiro Hiraguri, Eiko Nakazono-Nagaoka, Tamaki Uehara-Ichiki, \\ Masami Nakajima, Katsumi Akutsu, Toshihiro Omura, and Takahide Sasaya
}

\begin{abstract}
First, second, third, fourth, fifth, eighth, and ninth authors: National Agricultural Research Center, Tsukuba, Ibaraki 305-8666, Japan; and second, sixth, and seventh authors: Ibaraki University, Graduate School of Agriculture, Ami, Ibaraki 300-0393, Japan.

Current address of T. Sasaya: Kyushu Okinawa Agricultural Research Center, Koshi, Kumamoto 861-1192, Japan.

Accepted for publication 20 November 2012.
\end{abstract}

\begin{abstract}
Shimizu, T., Ogamino, T., Hiraguri, A., Nakazono-Nagaoka, E., UeharaIchiki, T., Nakajima, M., Akutsu, K., Omura, T., and Sasaya, T. 2013. Strong resistance against Rice grassy stunt virus is induced in transgenic rice plants expressing double-stranded RNA of the viral genes for nucleocapsid or movement proteins as targets for RNA interference. Phytopathology 103:513-519.

Rice grassy stunt virus (RGSV), a member of the genus Tenuivirus, causes significant economic losses in rice production in South, Southeast, and East Asian countries. Growing resistant varieties is the most efficient method to control RGSV; however, suitable resistance genes have not yet been found in natural rice resources. One of the most promising methods

It is important to target viral genes that play important roles in viral infection and proliferation at an early stage of viral replication. Our recent findings obtained from an RNAi experiment with Rice stripe virus (RSV), a tenuivirus, revealed that the genes for nucleocapsid and movement proteins were appropriate targets for RNAi to confer resistance against RSV. In this study, we transformed rice plants by introducing an RNAi construct of the RGSV genes for the nucelocapsid protein pC5 or movement protein pC6. All progenies from self-fertilized transgenic plants had strong resistance against RGSV infection and did not allow the proliferation of RGSV. Thus, our strategy to target genes for nucleocapsid and movement proteins for conferring viral resistance might be applicable to the plant viruses in the genus Tenuivirus.
\end{abstract} to confer resistance against RGSV is the use of RNA interference (RNAi).
Genetic engineering of crop plants using virus-derived genes to confer resistance is a well-established procedure that results in pathogen-derived resistance (38). Over the past 15 years, one of the most efficient methods to confer resistance against plant RNA viruses on their respective crops is RNA silencing, also known as RNA interference (RNAi) $(11,27,35)$. RNAi, an evolutionarily conserved process that is active in a wide variety of eukaryotic organisms, is a sequence-specific gene-silencing mechanism triggered by double-stranded RNA (dsRNA) $(2,49)$. As hairpin constructs $(28,51,52)$, dsRNA can be expressed in plants relatively easily, enabling us to apply this technology to a wide range of species to silence the expression of both specific endogenous genes and genes of invading pathogens (27). Attempts to engineer RNAi-mediated resistance to several plant viruses have achieved varying degrees of success, ranging from immunity to delayed symptoms to no resistance $(3,12,14,24,34,36,37,39-42,50)$. Our recent findings revealed that it is important to identify appropriate viral gene targets for RNAi such as those genes that play important roles in viral infection and proliferation at an early stage of viral replication $(41,42)$.

Rice grassy stunt virus (RGSV) causes significant economic losses in rice production in South, Southeast, and East Asian countries $(19,30)$. Recently, more than 485,000 ha of paddy field were severely affected by infection with RGSV or co-infection of RGSV with Rice ragged stunt virus (RRSV) in southern Vietnam,

Corresponding author: T. Sasaya; E-mail address: tsasaya@affrc.go.jp

http://dx.doi.org/10.1094/PHYTO-07-12-0165-R

(c) 2013 The American Phytopathological Society resulting in the loss of 828,000 tons of rice valued at US\$120 million and directly affecting millions of rice farmers in Vietnam $(5,6)$.

Infection of rice plants by RGSV leads to severe stunting of plant growth with profuse tillering, resulting in considerable decreases in grain yield. RGSV is transmitted to rice plants in a persistent manner by the brown planthopper (BPH), Nilaparvata lugens (Stål), which is a serious insect pest of rice (18). The virus replicates in the insect vector but is not transmitted transovarially to progeny (18).

Rice cultivars with various forms of resistance against the insect vector $N$. lugens have been planted widely in Asian countries (13). However, new biotypes of the insect vector that can overcome the resistance have often appeared after release of the resistant cultivars (10). Once insect populations have arisen that can feed on and colonize the cultivars containing the resistance gene, these cultivars are easily infected with RGSV. Additionally, rice cultivars with the resistance gene to RGSV derived from a wild rice species, Oryza nivara, have been used extensively in tropical Asia (25) but a severe strain of RGSV that occurred in the Philippines is highly virulent on these cultivars and the wild rice species $(7,20)$. Thus, the period of usefulness of such resistance cultivars against RGSV is limited, and the development of genetic engineering strategies may solve the urgent need to control RGSV.

RGSV belongs to the genus Tenuivirus, which includes Rice stripe virus (RSV) as the type species $(18,43)$. RGSV particles are thread-like, 6 to $8 \mathrm{~nm}$ wide, and mostly circular, with a contour length of 200 to $2,400 \mathrm{~nm}$ (18). The particles are ribonucleoproteins, which are composed of the RNA genome, nucleocapsid protein (NP), and RNA-dependent RNA polymerase (RdRp) (46). 
The genome of RGSV consists of six single-stranded RNA segments, which are designated RNAs 1 to 6 in order of decreasing molecular mass, and encodes 12 proteins $(30,47,48)$. All segments contain two open reading frames (ORFs), each in an ambisense arrangement. One ORF is located at the $5^{\prime}$ end of the viralsense RNA (vRNA), while another is located at the $5^{\prime}$ end of the viral complementary-sense RNA (vcRNA). vRNA 1 encodes p1 protein, whose function is unknown, and vcRNA 1 encodes $\mathrm{pC} 1$ protein, which is a putative viral $\operatorname{RdRp}(48)$. The functions of the products from the ORFs of RNAs 2 to 6 are largely unknown, except for vcRNA 5, which encodes pC5, an NP (47), and vcRNA 6, which encodes pC6, a movement protein (MP) (21).

During our attempts at developing resistance to RSV in rice plants, we analyzed the utility of potential target sequences in each of the coding regions of the RSV genome, using transgenic rice plants that expressed corresponding RNAi constructs. Transgenic plants that harbored an RNAi construct specific either for the gene for $\mathrm{pC} 3$, an NP, or for the gene for $\mathrm{pC} 4$, an MP, had strong resistance to infection by RSV (41). These results encouraged us to make transgenic rice plants that expressed an inverted repeat (IR) construct of the genes for either RGSV pC5 or pC6, that are the functional orthologs of pC3 and pC4 of RSV and might be appropriate targets for suppression of the proliferation of RGSV in infected rice plants.

In this study, we analyzed the effects of target sequences that corresponded to each of the RGSV genes for pC5 and pC6, using transgenic rice plants that expressed an IR construct. We demonstrated that the expression of viral dsRNA for targeting the genes for either NP or MP is an efficient method for developing resistance to RGSV in transgenic rice plants.

\section{MATERIALS AND METHODS}

Virus materials. RGSV, which was obtained from rice in the Kyushu area of Japan (44), was maintained in rice plants ('Nipponbare') and used as a source of inoculum and templates for reversetranscription polymerase chain reaction (RT-PCR). Young instar nymphs of $\mathrm{BPH}$ were allowed 2 days of acquisition access feeding on the RGSV-infected rice plants and reared on healthy rice seedlings for 20 days at $25 \pm 3^{\circ} \mathrm{C}$ during a latent infection period. To confirm the percentage of viruliferous insects, we tested the $20 \mathrm{BPHs}$ individually in double-antibody sandwich (DAS) enzyme-linked immunosorbent assays (ELISAs) (44). RSV was maintained in viruliferous vector insects, the small brown planthopper (SBPH) (Laodelphax striatellus Fallén), as described previously (44).

Construction of plasmids. For generating RNAi-inducing constructs, 500-bp fragments from the $5^{\prime}$-proximal regions of the genes for pC5 and pC6 of RGSV (Trigger_pC5 and Trigger_pC6, respectively) were amplified by RT-PCR with the RGSV-specific primer pairs (Table 1). Each of the forward primers contained CACC at the $5^{\prime}$ end for directional TOPO cloning (Invitrogen,

\section{TABLE 1. Primers used in this work}

\begin{tabular}{ll}
\hline Primer $^{\text {a }}$ & \multicolumn{1}{c}{ Sequence } \\
\hline $\begin{array}{l}\text { For RNA silencing } \\
\text { constructs }\end{array}$ & \\
Trigger_pC5-F & 5'-CACCATGGGTAAAGTGCAATTTGGAG-3' \\
Trigger_pC5-R & 5'-TATCAACGGTACTAATGGGTCT-3' \\
Trigger_pC6-F & 5'-CACCATGGCTTTACTCCAAAAGCTAG-3' $^{\prime}$ \\
Trigger_pC6-R & 5'-TCGGACAGGTAAGACAAGTCT-3' $^{\prime}$ \\
gus linker-specific & \\
GUS-F & 5'-CATGAAGATGCGGACTTACG-3' \\
GUS-R & 5'-ATCCACGCCGTATTCGG-3' \\
Actin-specific primers & \\
ACT-F & 5'-TCCATCTTGGCATCTCTCAG-3' \\
ACT-R & 5'-GTACCCGCATCAGGCATCTG-3' \\
\hline
\end{tabular}

a Abbreviation: gus $=\beta$-glucuronidase .
Life Technologies, Carlsbad, CA). The products were subcloned into a Gateway entry vector, the pENTR/D-TOPO (Invitrogen). The final RNAi vectors were produced by an LR Clonasecatalyzed reaction (Invitrogen) between these entry vectors and a Gateway destination vector, pANDA $(28,29)$ for transformation of rice calli, according to the manufacturer's instructions. Each resulting plasmid was separately introduced into Agrobacterium tumefaciens EHA101.

To prepare templates for riboprobes for detection of short interfering RNAs (siRNAs), we subcloned the aforementioned products of PCR into the pGEM-T cloning vector (Promega Corp., Madison, WI) to allow synthesis of RNA transcripts from either strand of the SP6 and T7 RNA polymerase promoters.

Transformation of rice calli. Mature seed of japonica rice (Nipponbare) were used in this study. Rice calli were subjected to Agrobacterium-mediated transformation according to a published method (45). Transformants were selected on a medium containing hygromycin B (50 mg/liter). Regenerated plants $\left(\mathrm{T}_{0}\right.$ generation) from hygromycin-resistant calli were eventually transferred to commercial soil (Bonsol; Sumitomo Chemical, Tokyo) in pots and grown to maturity in a greenhouse at $25 \pm 3^{\circ} \mathrm{C}$ with natural light.

Screening by PCR. For multiplex PCR screening of transgenic lines, genomic DNA was extracted from all plants $\left(\mathrm{T}_{0}\right.$ and $\mathrm{T}_{1}$ generations) used in this study by the following method. Rice leaves were mixed in a $2-\mathrm{ml}$ tube containing four $3.0-\mathrm{mm}$ stainless beads with $100 \mu \mathrm{l}$ each of Tris-EDTA (TE) buffer (10 mM Tris$\mathrm{HCl}$ and $1 \mathrm{mM}$ EDTA, pH 8.0) and TE-saturated phenol-chloroform (24:1), then ground using a Multi-beads shocker (Yasui Kikai Corp., Osaka, Japan). After centrifugation at 15,000 rpm for $5 \mathrm{~min}$, the supernatant was directly used as a DNA template for PCR analysis. To amplify the transgene-specific $\beta$-glucuronidase (gus) linker and an endogeneous rice gene for actin, we used the following primers: GUS-F, GUS-R, ACT-F, and ACT-R (Table 1).

Isolation and detection of siRNAs. The second-youngest leaf was collected from each plant at the six-leaf stage. After we harvested the samples, they were flash frozen in liquid nitrogen and then ground in the Multi-beads shocker. Total RNA was isolated from leaves of rice by using TRIzol Reagent (Invitrogen) according to the manufacturer's instructions. Total RNA $(\approx 2 \mu \mathrm{g})$ was fractionated on a $15 \%$ polyacrylamide $7 \mathrm{M}$ urea gel, as described by Hamilton et al. (16). After blotting onto a Hybond-N+ membrane (GE Healthcare, Little Chalfont, Buckinghamshire, UK), bands of RNA were visualized by staining with methylene blue, and 5.8S rRNA was used to confirm loading of equal amounts of RNA in each lane. Hybridization was performed at $40^{\circ} \mathrm{C}$ overnight in an ULTRAhyb-Oligo Hybridization Buffer (Ambion, Life Technologies, Carlsbad, CA) with a transgenespecific riboprobe. Riboprobes corresponding to Trigger_pC5 and Trigger_pC6 were prepared with T7 RNA polymerase from appropriate pGEM-T-based subclones using a digoxigenin (DIG) RNA Labeling Kit (Roche Diagnostics GmbH, Mannheim, Germany). Northern blotting analysis was performed with a DIG detection system (Roche Diagnostics $\mathrm{GmbH}$ ), and hybridization signals were detected with a Lumino Image Analyzer (LAS-4000 mini; Fujifilm, Tokyo) according to the manufacturer's instructions.

Assessment of resistance to RGSV and RSV. To evaluate the response to infection by RGSV, we inoculated transgenic plants $\left(\mathrm{T}_{1}\right.$ generation) and wild-type rice plants (Nipponbare) with homologous RGSV. In brief, 10-day-old rice seedlings were exposed to $\approx 10$ vector insects ( 20 to $30 \%$ of RGSV-carrying $\mathrm{BPH})$ per plant in an inoculation chamber $(70 \mathrm{~cm}$ wide by $70 \mathrm{~cm}$ deep by $75 \mathrm{~cm}$ high) for 1 day. After the inoculation period, the BPHs were killed with insecticide (Kadan-A; Fumakilla, Tokyo), and plants were transferred to an insect-free greenhouse at $25 \pm$ $3^{\circ} \mathrm{C}$ for development and evaluation of symptoms. Developing 
rice leaves were monitored daily for symptom expression caused by RGSV infection for $\approx 4$ months until harvest. To test whether resistance is extended to another tenuivirus, RSV, we inoculated the transgenic plants $\left(\mathrm{T}_{1}\right.$ generation) with RSV and symptoms caused by RSV infection were evaluated as described in our previous publications (41). For mock inoculation, wild-type rice seedlings were exposed to nonviruliferous (virus-free) BPHs or SBPHs instead of the viruliferous insects as described above.

Detection of RGSV by ELISA. To evaluate RGSV infection, we harvested pieces $(\approx 100 \mathrm{mg})$ of leaf sheath plus stem tissue from RGSV-inoculated rice plants at 7 weeks postinoculation (wpi). These samples were flash-frozen in liquid nitrogen, then ground in the Multi-beads shocker. The ground samples were suspended in 10 volumes of phosphate-buffered saline (PBS) (137 mM NaCl, 8.1 mM Na $2 \mathrm{HPO}_{4}, 2.7 \mathrm{mM} \mathrm{KCl}$, and $1.5 \mathrm{mM}$ $\mathrm{KH}_{2} \mathrm{PO}_{4}, \mathrm{pH} 7.4$ ). Each sap extract was then diluted 20 -fold with PBS and subjected to DAS-ELISA using an antiserum against RGSV, as described by Takahashi et al. (44).

\section{RESULTS}

Accumulation of transgene-specific siRNAs in the $\mathbf{T}_{\mathbf{0}}$ generation. To generate an RNAi-inducing construct, we cloned a DNA fragment of a 500-nucleotide (nt) region of either Trigger_pC5 or Trigger_pC6 (Fig. 1A) into the vector pANDA that would transcribe hairpin RNA (hpRNA). These trigger fragments were inserted into two sites in opposite directions, separated by the gus linker sequence, and driven by the promoter of the maize (Zea mays) gene for ubiquitin (9) (Fig. 1B). The RNAi constructs were introduced into rice calli derived from an RGSV-susceptible rice cultivar (Nipponbare). By selection for hygromycin resistance, 16 transgenic plants from independent,

A

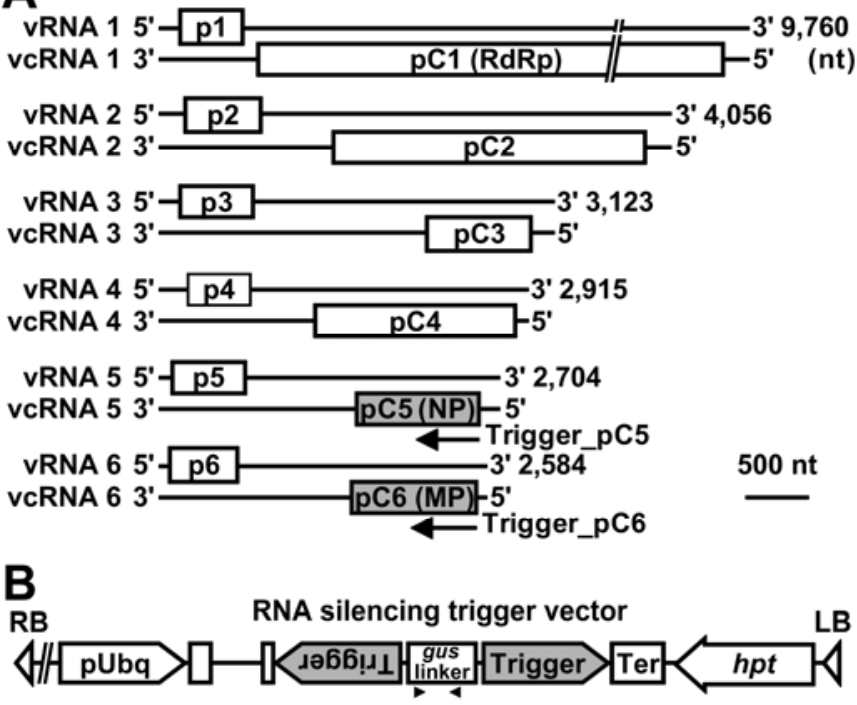

Fig. 1. Structure of Rice grassy stunt virus (RGSV) genome and an RNAsilencing trigger vector. A, Genetic map of RNAs 1 to 6 of the RGSV genome. Lines represent RNA segments; boxes denote genes encoded by the viralsense RNAs (vRNAs) and viral complementary-sense RNAs (vcRNAs). Arrows indicate origins of fragments that were amplified and cloned into the vector for plant transformation. RdRp: RNA-dependent RNA polymerase; NP: nucleocapsid; MP: movement protein. B, Schematic representation of constructs for RGSV-specific RNA interference (RNAi). Each of two fragments (Trigger_pC5 and Trigger_pC6) derived from RNAs 5 and 6 were cloned in two orientations in pANDA to trigger RNAi. Transcripts of the RNAi-trigger region were designed to be expressed constitutively under the control of the promoter $(\mathrm{pUbq})$ of the maize gene for ubiquitin. Downstream of $\mathrm{pUbq}$, the two unlabeled boxes represent exons, and the thin line separating the exons marks an intron of the ubiquitin $(U b q)$ gene. Small arrowheads indicate position of primers used to detect a transgene. transformed calli were obtained, and the presence of the transgene in the genome DNA was confirmed by PCR analysis (data not shown).

We selected three lines each that accumulated siRNAs specific to Trigger_pC5 or to Trigger_pC6, which migrated as RNA molecules of 21 to $24 \mathrm{nt}$, from PCR-positive transgenic $\mathrm{T}_{0}$ rice plants (Fig. 2). Then, these transgenic $\mathrm{T}_{0}$ plants were self fertilized, and $\mathrm{T}_{1}$ progeny were generated for further analysis of the resistance against RGSV.

Strong resistance against RGSV in transgenic rice plants that harbored either pC5- or pC6-specific sequences. To evaluate the response to infection by RGSV, we exposed transgenic $\mathrm{T}_{1}$ plants to the viruliferous BPHs, using wild-type plants as controls. The $\mathrm{T}_{1}$ progeny from each of the three transgenic lines that harbored either Trigger_pC5 or Trigger_pC6 were significantly resistant to RGSV infection (Fig. 3; Table 2). All the plants that were asymptomatic at $4 \mathrm{wpi}$, when all infected wild-type plants had typical stunting symptoms, continued to be symptomfree until harvest, similar to those that were mock inoculated (Fig. 4). The extent of the resistance to RGSV was similar among plants in each progeny line, regardless of whether the transgene corresponded to Trigger_pC5 or Trigger_pC6. In addition, no apparent differences in morphology or growth, based on plant height, number of tillers (Fig. 4), and rice grain yields (data not shown), were observed between transgenic and mock-inoculated, nontransgenic wild-type rice plants. Not all the wild-type control plants were infected (Table 2), and some escaped from infection, as observed previously (39-42). In all, 28 transgenic $\mathrm{T}_{1}$ plants from line 1 of the Trigger_pC5 had inherited a transgene and showed resistance to RGSV infection, whereas eight $T_{1}$ plants

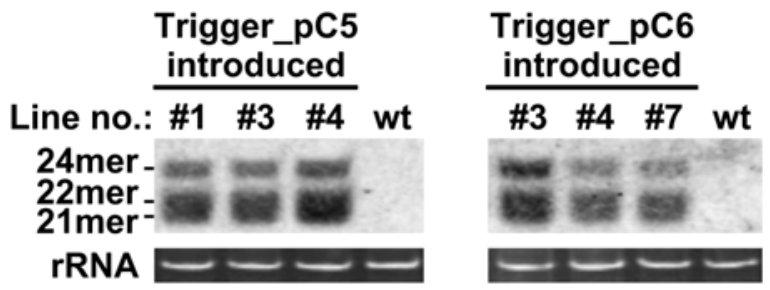

Fig. 2. Northern blot detection of Rice grassy stunt virus (RGSV) pC5- or pC6-specific short interfering RNAs in noninoculated primary transgenic plants. Total RNA $(\approx 2 \mu \mathrm{g})$, extracted separately from three independent lines of transgenic plants that harbored either Trigger_pC5 or Trigger_pC6, were probed with digoxigenin-labeled Trigger_pC5- or Trigger_pC6-specific RNA. Wild-type (wt) rice plants ('Nipponbare') were used as controls. The lower panel shows the detection of 5.8S rRNA, used as a control to confirm loading of equal amounts of RNA in each lane.

TABLE 2. Reactions of susceptible wild-type rice cultivar and $\mathrm{T}_{1}$ generation of transgenic rice plants that harbor Trigger_pC5 and Trigger_pC6 for RNA interference after inoculation with Rice grassy stunt virus (RGSV)

\begin{tabular}{llcc}
\hline & & \multicolumn{2}{c}{ Number of test plants $^{\mathrm{c}}$} \\
\cline { 3 - 4 }${\text { Plant, } \mathrm{T}_{0}{ }^{\mathrm{a}}}^{\mathrm{b}}$ & $n^{\mathrm{b}}$ & $\mathrm{S}$ & $\mathrm{R}$ \\
\hline Trigger_pC5 & 32 & $8^{\mathrm{d}}$ & 24 \\
1 & 33 & $7^{\mathrm{d}}$ & 26 \\
3 & 34 & $3^{\mathrm{d}}$ & 31 \\
4 & & & \\
Trigger_pC6 & 34 & $2^{\mathrm{d}}$ & 32 \\
3 & 30 & $7^{\mathrm{d}}$ & 23 \\
4 & 33 & $9^{\mathrm{d}}$ & 24 \\
7 & 68 & 64 & $4^{\mathrm{f}}$ \\
Wild-type & & &
\end{tabular}

${ }^{a} \mathrm{~T}_{0}=$ parent line number.

b Number of rice plants examined.

c S: typical symptoms induced by RGSV infection at 4 weeks postinoculation;

$\mathrm{R}$ : plants remained symptomless for the 7-week test.

d None of the plants inherited the transgene when tested with PCR.

e 'Nipponbare' used as controls.

f Plants that escaped infection by RGSV. 
from this line did not inherit a transgene and they induced symptoms of RGSV infection (Fig. 5A). Of 196 analyzed transgenic $T_{1}$ plants from each of three lines, none of the transgenic plants that showed infection with RGSV harbored a transgene (data not shown), as was the case for line 1 of the Trigger_pC5 $T_{1}$ plants described.

To verify the resistance to RGSV infection in the transgenic rice plants, sap extracts of the leaf sheaths plus stem from each plant were examined separately for the presence of RGSV by DAS-ELISA with an antiserum to the RGSV particle at 7 wpi. We were unable to detect RGSV in 28 transgenic $T_{1}$ plants from line 1 of Trigger_pC5 that inherited a transgene (Fig. 5). By contrast, in eight $\mathrm{T}_{1}$ plants from this line that had not inherited a transgene, RGSV was detected at levels as high as those in the control wild-type plants (Fig. 5). We obtained similar results; RGSV was not detected in the transgenic $T_{1}$ plants that had inherited a transgene and did not induce symptoms of RGSV infection, whereas the transgenic plants that showed infection with RGSV did not harbor a transgene (data not shown).

No resistance to other tenuiviruses in transgenic rice plants that expressed either RGSV pC5- or pC6-specific siRNAs. To evaluate the response to infection by other tenuiviruses, we inoculated progeny $T_{1}$ plants from each transgenic line generated with Trigger_pC5 or Trigger_pC6 with RSV and monitored the RSV infection daily by symptom development. Of these, $95.7 \%$ of the Trigger_pC5 and $94.4 \%$ of the Trigger_pC6 transgenic plants, almost the same as the wild-type rice plants, were susceptible to RSV infection (Table 3). Symptoms induced by RSV infection in the transgenic lines with Trigger_pC5 and Trigger_pC6 were as severe as those on the wild-type rice plants (Fig. 6).

\section{DISCUSSION}

RNAi, an antiviral defense mechanism in plants, can be exploited in transgenic plants to preprogram recognition of plant viruses and to confer enhanced resistance to infection by plant viruses. A correlation between the presence of virus-specific siRNAs and resistance to the respective viruses has been reported in several studies $(8,24,31)$. RNAi has been considered as an

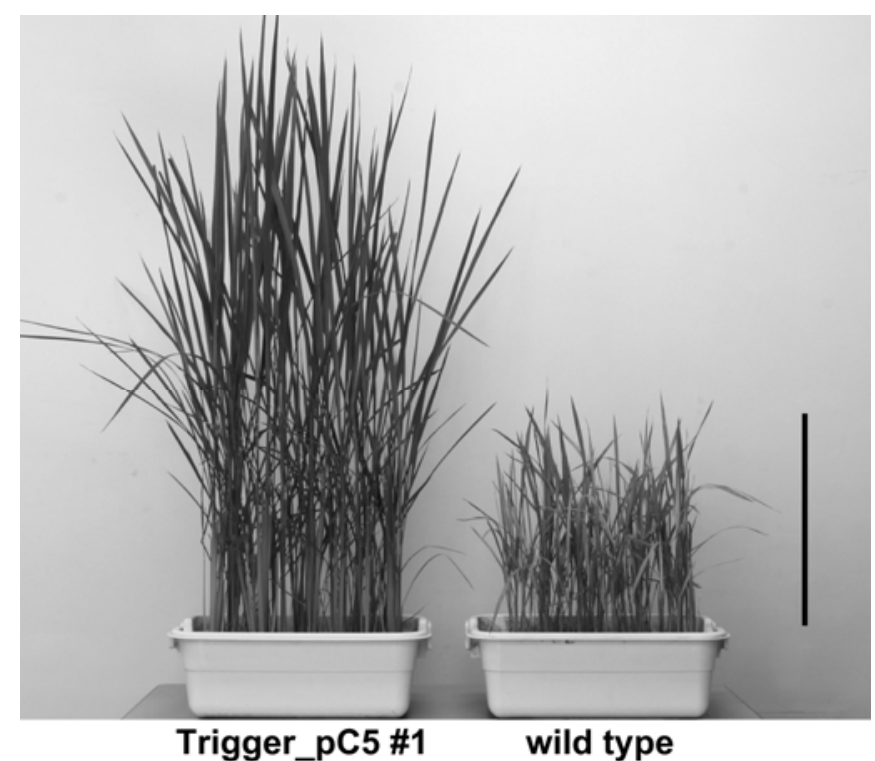

Fig. 3. Phenotypes of transgenic and wild-type rice plants 7 weeks postinoculation with Rice grassy stunt virus (RGSV). Plants in containers from left to right are: RGSV-resistant progeny $\left(\mathrm{T}_{1}\right)$ of line 1 of transgenic rice plants that harbored pC5-targeting trigger sequence exposed to viruliferous insects, showing healthy growth after RGSV inoculation; RGSV-susceptible nontransgenic wild-type rice plants ('Nipponbare') inoculated with viruliferous insects, showing typical stunting after RGSV infection. Bar: $30 \mathrm{~cm}$. important tool to render plants resistant to plant virus infections. In addition, the levels of resistance achieved have varied from complete resistance to a delay in symptom expressions or an absence of resistance. Recently, by analyzing the effects of potential target sequences in each of the coding genes in the genome of RSV, a tenuivirus, using transgenic rice plants that expressed a set of IR constructs, transgenic plants that harbored the IR construct specific for either the gene for the $\mathrm{pC} 3$, NP $(26,33,41)$, or the gene for the $\mathrm{pC} 4$, MP (41), were completely resistant to infection by RSV, suggesting that these proteins are key components at the early stages of viral proliferation. By contrast, transgenic plants that harbored the IR construct specific for either the gene for $\mathrm{pC} 2$, a glycoprotein of unknown function, or the gene for $\mathrm{p} 4$, a major nonstructural protein of unknown function, were susceptible to infection by RSV. These proteins might not be essential for viral proliferation in rice plants or might function in the vector insects. These results indicated that not all RNAi constructs against viral RNAs are equally effective in preventing viral infection and that it is important to identify the viral "Achilles heel" for RNAi attack in the engineering of plants.

In the present study, our transgenic plants that harbored the IR construct specific for the RGSV gene for $\mathrm{pC} 5$, an NP and a functional ortholog of RSV pC3 (47), exhibited a strong resistance that was near immunity against RGSV infection. Transgenic rice plants that remained asymptomatic after challenge with RGSV did not contain detectable amounts of the virus, as determined by ELISA. In the case of viruses in the genera Tospovirus and Ophiovirus, which are plant-infecting, segmented negative-stranded RNA viruses, transgenic plants that harbored IR constructs specific for the gene for NP also resulted in strong resistance to these viruses $(4,36)$. Taken together, the gene for NPs seems to be one of the most promising candidate genes for RNAi in efforts to confer resistance not only to tenuiviruses but also to other negativestranded viruses.

Development of local and systemic infection by a plant virus requires the transfer of the virus from the initially infected cells to the adjacent neighboring cells and, eventually, systemic spread of the virus throughout the plant. MPs have been identified in plant viruses in most virus families and, in most cases, they perform functions dedicated to intercellular movement. If the virus is unable to express an MP, the infection will be contained in the

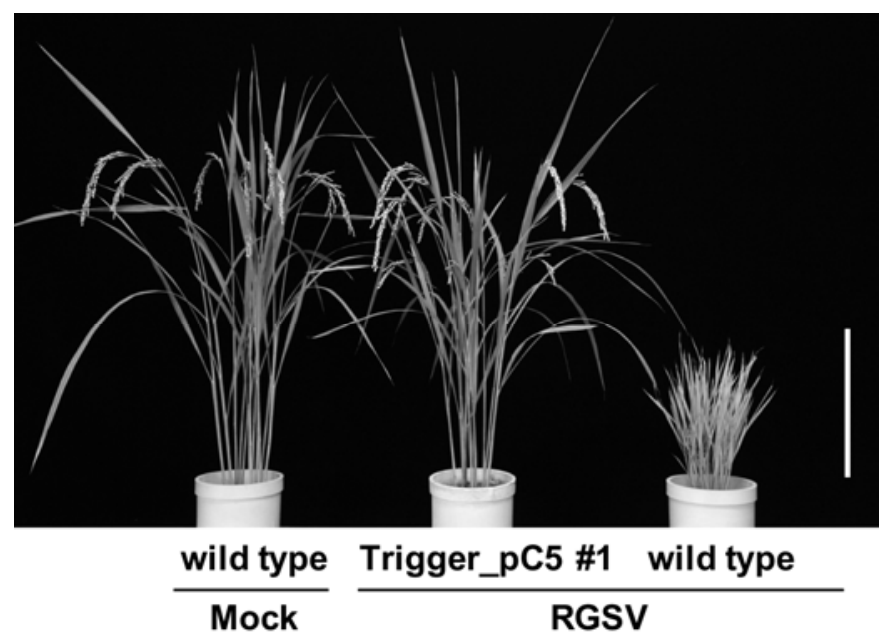

Fig. 4. Phenotypes of transgenic and wild-type rice plants inoculated with Rice grassy stunt virus (RGSV) at harvest (15 weeks postinoculation). Plants in pots from left to right are: mock-inoculated nontransgenic wild-type rice plants ('Nipponbare') exposed to virus-free brown planthoppers, showing normal growth; RGSV-resistant progeny $\left(\mathrm{T}_{1}\right)$ of line 1 of transgenic rice plant that harbored pC5-targeting trigger sequence, showing healthy growth and fertility after RGSV inoculation; RGSV-susceptible nontransgenic wild-type rice plant, showing typical stunting and profuse tillering after RGSV infection. Bar: $30 \mathrm{~cm}$. 
primary infected cells and, consequently, these plants are expected to appear resistant owing to the blockage of viral cell-tocell movement. Our transgenic plants that harbored the IR construct specific for the RGSV gene for pC6, an MP and a functional ortholog of RSV pC4 $(21,47)$ were also strongly resistant to RGSV infection and did not accumulate any detectable virus. This resistance to RGSV infection was most likely due to efficient interference with viral cell-to-cell movement. Compared with reports on viral coat protein genes as targets for RNAi-mediated resistance in plants, far fewer reports have focused on the viral gene for the MP as an RNAi target $(22,41)$. However, our results suggest that the gene for MP is also likely to be a potential candidate for RNAi in efforts to confer resistance to other negative-stranded viruses.

Based on our successes in conferring resistance to other rice viruses in rice plants (39-42), we adjusted the arm length of $500 \mathrm{bp}$ for hpRNA constructs in this study. The transgenic plants accumulated three size classes of transgene-specific siRNAs as a molecular marker of RNAi process, demonstrating that the artificially expressed dsRNA was recognized and cleaved by the processing enzyme Dicer. The gross morphology of the transgenic plants and noninoculated wild-type rice plants did not differ significantly, suggesting that genes important for the growth of rice plants were not disturbed. Moreover, the RGSV-resistant rice

TABLE 3. Reactions of susceptible wild-type rice cultivar and $T_{1}$ generation of transgenic rice plants that harbor Trigger_pC5 and Trigger_pC6 for RNA interference after inoculation with Rice stripe virus (RSV)

\begin{tabular}{llll}
\hline & & \multicolumn{2}{c}{ Number of test plants $^{\mathrm{c}}$} \\
\cline { 3 - 4 } Plant, $_{0}{ }^{\mathrm{a}}$ & $n^{\mathrm{b}}$ & $\mathrm{S}$ & $\mathrm{R}$ \\
\hline Trigger_pC5 & & 30 & 2 \\
1 & 32 & 26 & 1 \\
3 & 27 & 32 & 1 \\
4 & 33 & 28 & 2 \\
Trigger_pC6 & & 29 & 2 \\
3 & 30 & 28 & 1 \\
4 & 31 & 32 & $2^{\mathrm{e}}$ \\
7 & 29 & &
\end{tabular}

a $\mathrm{T}_{0}=$ parent line number.

b Number of rice plants examined.

${ }^{c}$ S: typical symptoms induced by RSV infection at 4 weeks postinoculation;

$\mathrm{R}$ : plants remained symptomless for the 7-week test.

d 'Nipponbare' used as controls.

e Plants that escaped infection by RSV. plants were not resistant to challenge inoculation with RSV, which is serologically distantly related to RGSV, probably because the nucleotide sequences identities between RGSV and RSV in the genes for NP and MP were only 48.6 and $48.8 \%$, respectively. Our results demonstrate that our designed trigger inhibits specifically RGSV infection without disturbing the growth of rice plants, as observed in the case of phytoreoviruses (40).

The spectrum of the RNA-mediated virus resistance is generally restricted to viral strains with $>\approx 90 \%$ sequence identities to the introduced transgenes $(1,17,23,32)$. When we compared the nucleotide sequences of the genes for the NP and the MP between our strain and all the strains of RGSV that are available in DDBJ/EMBL/GenBank, the 500 bp of target sequences that corresponded to each of the partial RGSV genes for NP and MP used for cloning and transformation share 96.6 to 99.0 and 97.4 to 98.6\% nucleotide sequence identities, respectively, with those of other RGSV strains. Thus, it seems that our transgenic plants

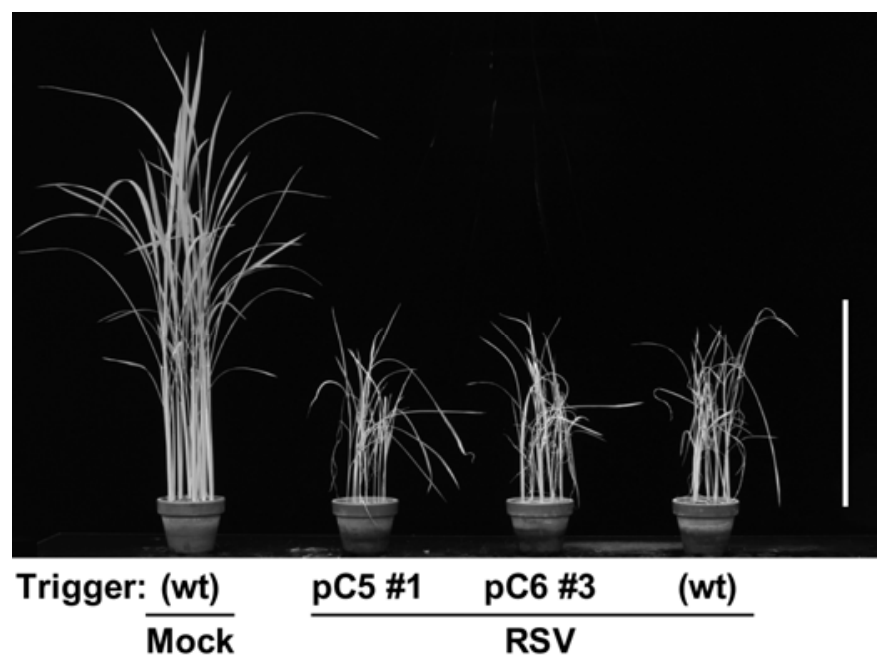

Fig. 6. Phenotypes of transgenic and wild-type (wt) rice plants 7 weeks postinoculation with Rice stripe virus (RSV). From left to right: mock-inoculated nontransgenic wt rice plants ('Nipponbare') exposed to virus-free small brown planthoppers, showing normal growth; Rice grassy stunt virus-resistant progenies $\left(\mathrm{T}_{1}\right)$ of transgenic rice plants that harbored pC5- and pC6-targeting trigger sequences, respectively, showing severe symptoms after RSV inoculation; RSVsusceptible nontransgenic wt rice plants, showing severe symptoms after RSV inoculation. Bar: $30 \mathrm{~cm}$.

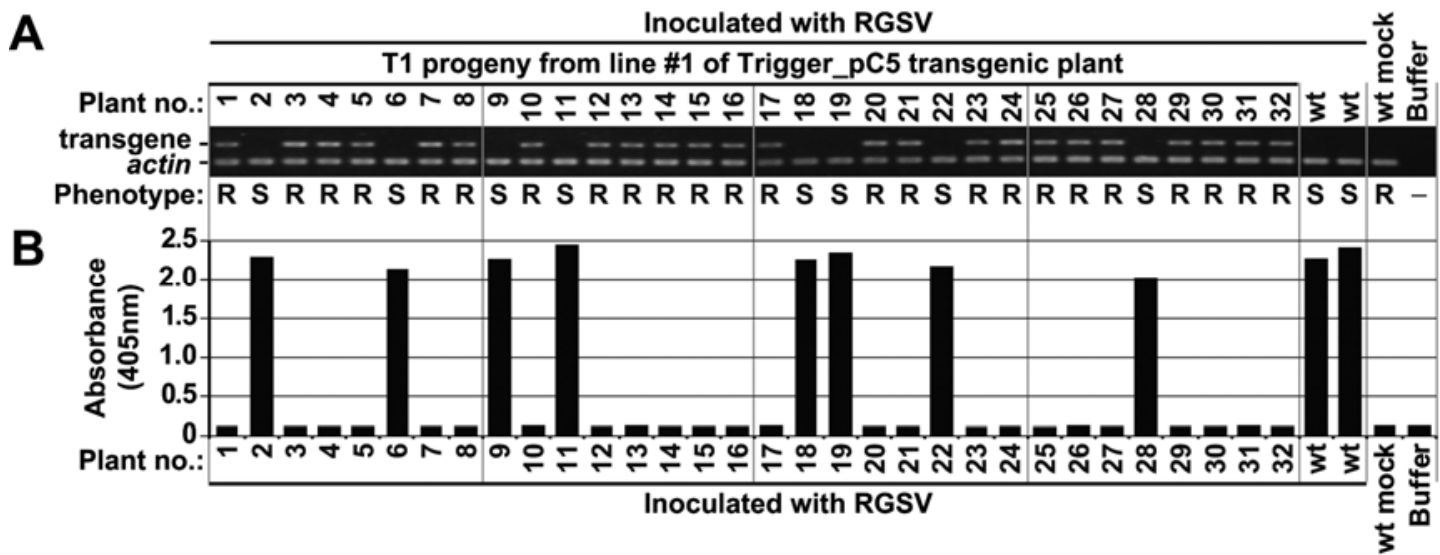

Fig. 5. Correlation between inheritance of a transgene and Rice grassy stunt virus (RGSV) accumulation in a population of segregating progeny from line 1 of Trigger_pC5 transgenic rice plant. A, Polymerase chain reaction (PCR) screening for the inheritance of a transgene. Genomic DNA from the transgenic and wildtype (wt) plant was analyzed by multiplex PCR with transgene-specific $\beta$-glucuronidase (gus) linker primers and with primers specific for an endogeneous rice gene for actin as a control. Numbers above lanes represent individual plants. Response to infection of each plant is indicated below the panel: R, plants remained symptomless (i.e., resistant) for the 7-week observation period; S, typical symptoms were observed 4 weeks postinoculation (wpi). B, Detection by enzyme-linked immunosorbent assay of RGSV particles in transgenic and wt rice plants 7 wpi. Values refer to absorbance at $405 \mathrm{~nm}$, measured after hydrolysis of substrate for 90 min. For wt mock inoculation, nontransgenic wt rice plants were exposed to virus-free brown planthoppers. 
possess a potentially durable, broad-spectrum resistance against heterologous strains of RGSV originating from different geographic regions.

Inevitably, RNAi can only target viral RNAs after the virus has entered the cells. For induction of strong resistance against viruses, choosing viral target genes that play an important role at the early stages of viral replication is important. During our attempts at developing resistance against plant reoviruses in rice plants using RNAi, we found that suppressing genes for the viroplasm, which is thought to be the site of viral replication and packaging into progeny particles, is effective in conferring resistance to a virus $(39,40,42)$. By contrast, we showed in this study that plants harboring an RNAi construct specific for the gene for either an NP or an MP were strongly resistant against RGSV infection, indicating that the choice of appropriate viral genes as targets for RNAi-mediated resistance in plants seems to differ among groups of viruses. Conversely, analysis of correlations between interference with the expression of the viralspecific genes and the induction of various levels of resistance in host plants might inform us about the functions of the viral proteins that play important roles in viral infection and proliferation at an early stage of viral replication. RNAi is a promising approach to investigate the functions of viral proteins, especially for viruses without established reverse genetics systems.

The recent disease epidemic caused by infection with RGSV or co-infection with RGSV and RRSV in the Mekong delta of southern Vietnam highlights the significant socioeconomic effects of crop diseases at a national level and in Asia $(19,30)$. Our findings described in this study should help to solve these problems and contribute greatly to ensuring a stable food supply in Asian countries burdened with RGSV disease. Furthermore, it also seems plausible that our strategy for interfering with the expression of the NP and MP can induce strong resistance against virus infection and should be effective for controlling other tenuiviruses such as Maize stripe virus and Rice hoja blanca virus, which cause important diseases in economically important crop plants (15).

\section{ACKNOWLEDGMENTS}

This work was supported by a grant from the Program for Promotion of Basic Research Activities for Innovative Biosciences of the BioOriented Technology Research Advancement Institution (BRAIN) and by a grant from the Ministry of Agriculture, Forestry, and Fisheries of Japan (Genomic for Agricultural Innovation, GMA-0003). We thank K. Shimamoto (Nara Institute of Science and Technology, Ikoma, Japan) for kindly providing the RNAi vector pANDA.

\section{LITERATURE CITED}

1. Bau, H. J., Cheng, Y. H., Yu, T. A., Yang, J. S., and Yeh, S. D. 2003. Broad-spectrum resistance to different geographic strains of Papaya ringspot virus in coat protein gene transgenic papaya. Phytopathology 93:112-120.

2. Baulcombe, D. 2005. RNA silencing. Trends Biochem. Sci. 30:290-293.

3. Bonfim, K., Faria, J. C., Nogueira, E. O. P. L., Mendes, É. A., and Aragão, F. J. L. 2007. RNAi-mediated resistance to Bean golden mosaic virus in genetically engineered common bean (Phaseolus vulgaris). Mol. PlantMicrobe Interact. 20:717-726.

4. Bucher, E., Lohuis, D., van Poppel, P. M. J. A., Geerts-Dimitriadou, C., Goldbach, R., and Prins, M. 2006. Multiple virus resistance at a high frequency using a single transgene construct. J. Gen. Virol. 87: 3697-3701

5. Cabauatan, P. Q., Cabunagan, R. C., and Choi, I.-R. 2009. Rice viruses transmitted by the brown planthopper Nilaparvata lugens Stål. Pages 357358 in: Planthoppers: New Threats to the Sustainability of Intensive Rice Production Systems in Asia. K. L. Heong and B. Hardy, eds. International Rice Research Institute, Los Baños, Philippines.

6. Cabunagan, R., and Choi, I.-R. 2009. Why outbreaks of virus diseases occurred in south Vietnam? Ricehoppers. http://ricehoppers.net/2009/06/ why-outbreaks-of-virus-diseases-occurred-in-south-vietnam/
7. Cabauatan, P. Q., Hibino, H., Lapis, D. B., Omura, T., and Tsuchizaki, T. 1985. Rice grassy stunt virus 2: a new strain of rice grassy stunt in the Philippines. IRRI Res. Pap. Ser. 106:8.

8. Chen, Y. K., Lohuis, D., Goldbach, R., and Prins, M. 2004. High frequency induction of RNA-mediated resistance against Cucumber mosaic virus using inverted repeat constructs. Mol. Breed. 14:215-226.

9. Christensen, A. H., Sharrock, R. A., and Quail, P. H. 1992. Maize polyubiquitin genes: Structure, thermal perturbation of expression and transcript splicing, and promoter activity following transfer to protoplasts by electroporation. Plant Mol. Biol. 18:675-89.

10. Claridge, M. F., and den Hollander, J. 1980. The "biotypes" of the rice brown planthopper, Nilaparvata lugens. Entomol. Exp. Appl. 27:23-30.

11. Collinge, D. B., Jørgensen, H. J., Lund, O. S., and Lyngkjær, M. F. 2010. Engineering pathogen resistance in crop plants: Current trends and future prospects. Annu. Rev. Phytopathol. 48:269-291.

12. Di Nicola-Negri, E., Brunetti, A., Tavazza, M., and Ilardi, V. 2005. Hairpin RNA-mediated silencing of Plum pox virus $\mathrm{P} 1$ and HC-Pro genes for efficient and predictable resistance to the virus. Transgenic Res. 14:989-994.

13. Du, B., Zhang, W., Liu, B., Hu, J., Wei, Z., Shi, Z., He, R., Zhu, L., Chen, R., Han, B., and He, G. 2009. Identification and characterization of Bph14, a gene conferring resistance to brown planthopper in rice. Proc. Natl. Acad. Sci. USA 106:22163-22168.

14. Fahim, M., Ayala-Navarrete, L., Millar, A. A., and Larkin, P. J. 2010. Hairpin RNA derived from viral NIa gene confers immunity to Wheat streak mosaic virus infection in transgenic wheat plants. Plant Biotechnol. J. 8:821-834.

15. Falk, B. W., and Tsai, J. H. 1998. Biology and molecular biology of viruses in the genus Tenuivirus. Annu. Rev. Phytopathol. 36:139-163.

16. Hamilton, A., Voinnet, O., Chappell, L., and Baulcombe, D. 2002. Two classes of short interfering RNA in RNA silencing. EMBO J. 21:46714679.

17. Hassani-Mehraban, A., Brenkman, A. B., van den Broek, N. J. F., Goldbach, R., and Kormelink, R. 2009. RNAi-mediated transgenic Tospovirus resistance broken by intraspecies silencing suppressor protein complementation. Mol. Plant-Microbe Interact. 22:1250-1257.

18. Hibino, H. 1986. Rice grassy stunt virus. CMI/AAB Descr. Plant Viruses No. 320.

19. Hibino, H. 1996. Biology and epidemiology of rice viruses. Annu. Rev. Phytopathol. 34:249-274.

20. Hibino, H., Cabauatan, P. Q., Omura, T., and Tsuchizaki, T. 1985. Rice grassy stunt virus strain causing tungrolike symptoms in the Philippines. Plant Dis. 69:538-541.

21. Hiraguri, A., Netsu, O., Shimizu, T., Uehara-Ichiki, T., Omura, T., Sasaki, N., Nyunoya, H., and Sasaya, T. 2011. The nonstructural protein pC6 of Rice grassy stunt virus trans-complements the cell-to-cell spread of a movement-defective Tomato mosaic virus. Arch. Virol. 156:911-916.

22. Hu, Q., Niu, Y., Zhang, K., Liu, Y., and Zhou, X. 2011. Virus-derived transgenes expressing hairpin RNA give immunity to Tobacco mosaic virus and Cucumber mosaic virus. Virology J. 8:41-51.

23. Jones, A. L., Johansen, I. E., Bean, S. J., Bach, I., and Maule, A. J. 1998. Specificity of resistance to pea seed-borne mosaic potyvirus in transgenic peas expressing the viral replicase (Nib) gene. J. Gen. Virol. 79:31293137.

24. Kalantidis, K., Psaradakis, S., Tabler, M., and Tsagris, M. 2002. The occurrence of CMV-specific short Rnas in transgenic tobacco expressing virus-derived double-stranded RNA is indicative of resistance to the virus. Mol. Plant-Microbe Interact. 15:826-833.

25. Khush, G. S., and Ling, K. C. 1974. Inheritance of resistance to grassy stunt virus and its vector in rice. J. Hered. 65:134-136.

26. Ma, J., Song, Y., Wu, B., Jiang, M., Kaidong, L., Zhu, C., and Wen, F. 2011. Production of transgenic rice new germplasm with strong resistance against two isolations of Rice stripe virus by RNA interference. Transgenic Res. 20:1367-1377.

27. Mansoor, S., Amin, I., Hussain, M., Zafar, Y., and Briddon, R. W. 2006. Engineering novel traits in plants through RNA interference. Trends Plant Sci. 11:559-565.

28. Miki, D., Itoh, R., and Shimamoto, K. 2005. RNA silencing of single and multiple members in a gene family of rice. Plant Physiol. 138:1903-1913.

29. Miki, D., and Shimamoto, K. 2004. Simple RNAi vectors for stable and transient suppression of gene function in rice. Plant Cell Physiol. 45:490495.

30. Miranda, G. J., Azzam, O., and Shirako, Y. 2000. Comparison of nucleotide sequences between northern and southern Philippine isolates of Rice grassy stunt virus indicates occurrence of natural genetic reassortment. Virology 266:26-32.

31. Missiou, A., Kalantidis, K., Boutla, A., Tzortzakaki, S., Tabler, M., and Tsagris, M. 2004. Generation of transgenic potato plants highly resistant to Potato virus $Y$ (PVY) through RNA silencing. Mol. Breed. 14:185-197.

32. Moreno, M., Bernal, J. J., Jiménez, I., and Rodríguez-Cerezo, E. 1998. 
Resistance in plants transformed with the P1 or P3 gene of tobacco vein mottling potyvirus. J. Gen. Virol. 79:2819-2827.

33. Park, H.-M., Choi, M.-S., Kwak, D.-Y., Lee, B.-C., Lee, J.-H., Kim, M.K., Kim, Y.-G., Shin, D.-B., Park, S.-K., and Kim, Y.-H. 2012. Suppression of NS3 and MP is important for the stable inheritance of RNAimediated Rice stripe virus (RSV) resistance obtained by targeting the fully complementary RSV-CP gene. Mol. Cells 33:43-51.

34. Patil, B. L., Ogwok, E., Wagaba, H., Mohammed, I. U., Yadav, J. S., Bagewadi, B., Taylor, N. J., Kreuze, J. F., Maruthi, M. N., Alicai, T., and Fauquet, C. M. 2011. RNAi-mediated resistance to diverse isolates belonging to two virus species involved in Cassava brown streak disease. Mol. Plant Pathol. 12:31-41.

35. Prins, M., Laimer, M., Noris, E., Schubert, J., Wassenegger, M., and Tepfer, M. 2008. Strategies for antiviral resistance in transgenic plants. Mol. Plant Pathol. 9:73-83.

36. Reyes, C. A., De Francesco, A., Peña, E. J., Costa, N., Plata, M. I., Sendin, L., Castagnaro, A. P., and García, M. L. 2011. Resistance to Citrus psorosis virus in transgenic sweet orange plants is triggered by coat protein-RNA silencing. J. Biotechnol. 151:151-158.

37. Ribeiro, S. G., Lohuis, H., Goldbach, R., and Prins, M. 2007. Tomato chlorotic mottle virus is a target of RNA silencing but the presence of specific short interfering RNAs does not guarantee resistance in transgenic plants. J. Virol. 81:1563-1573.

38. Sanford, J. C., and Johnston, S. A. 1985. The concept of parasite-derived resistance-driving resistance genes from the parasite's own genome. J. Theor. Biol. 113:395-405.

39. Shimizu, T., Nakazono-Nagaoka, E., Akita, F., Uehara-Ichiki, T., Omura, T., and Sasaya, T. 2011. Immunity to Rice black streaked dwarf virus, a plant reovirus, can be achieved in rice plants by RNA silencing against the gene for the viroplasm matrix protein. Virus Res. 160:400-403.

40. Shimizu, T., Nakazono-Nagaoka, E., Akita, F., Wei, T., Sasaya, T., Omura, T., and Uehara-Ichiki, T. 2012. Hairpin RNA derived from the gene for Pns9, a viroplasm matrix protein of Rice gall dwarf virus, confers strong resistance to virus infection in transgenic rice plants. J. Biotechnol. 157:421-427

41. Shimizu, T., Nakazono-Nagaoka, E., Uehara-Ichiki, T., Sasaya, T., and Omura, T. 2011. Targeting specific genes for RNA interference is crucial to the development of strong resistance to Rice stripe virus. Plant
Biotechnol. J. 9:503-512.

42. Shimizu, T., Yoshii, M., Wei, T., Hirochika, H., and Omura, T. 2009. Silencing by RNAi of the gene for Pns12, a viroplasm matrix protein of Rice dwarf virus, results in strong resistance of transgenic rice plants to the virus. Plant Biotechnol. J. 7:24-32.

43. Shirako, Y., Falk, B. W., and Haenni, A.-L. 2012. Genus Tenuivirus. Pages 771-776 in: Virus Taxonomy: Classification and Nomenclature of Viruses: Ninth Report of the International Committee on Taxonomy of Viruses. A M. Q. King, M. J. Adams, E. B. Carstens, and E. J. Lefkowitz, eds. Elsevier Academic Press, San Diego, CA.

44. Takahashi, Y., Omura, T., Shohara, K., and Tsuchizaki, T. 1991. Comparison of four serological methods for practical detection of ten viruses of rice in plants and insects. Plant Dis. 75:458-461.

45. Toki, S., Hara, N., Ono, K., Onodera, H., Tagiri, A., Oka, S., and Tanaka, H. 2006. Early infection of scutellum tissue with Agrobacterium allows high-speed transformation of rice. Plant J. 47:969-976.

46. Toriyama, S. 1987. RNA polymerase activity in filamentous nucleoproteins of rice grassy stunt virus. J. Gen. Virol. 68:925-930.

47. Toriyama, S., Kimishima, T., and Takahashi, M. 1997. The proteins encoded by rice grassy stunt virus RNA5 and RNA6 are only distantly related to the corresponding proteins of other members of the genus Tenuivirus. J. Gen. Virol. 78:2355-2363.

48. Toriyama, S., Kimishima, T., Takahashi, M., Shimizu, T., Minaka, N., and Akutsu, K. 1998. The complete nucleotide sequence of the rice grassy stunt virus genome and genomic comparisons with viruses of the genus Tenuivirus. J. Gen. Virol. 79:2051-2058.

49. Voinnet, O. 2005. Induction and suppression of RNA silencing: insights from viral infections. Nat. Rev. Genet. 6:206-220.

50. Wang, M. B., Abbott, D. C., and Waterhouse, P. M. 2000. A single copy of a virus-derived transgene encoding hairpin RNA gives immunity to Barley yellow dwarf virus. Mol. Plant Pathol. 1:347-356.

51. Waterhouse, P. M., Wang, M. B., and Lough, T. 2001. Gene silencing as an adaptive defence against viruses. Nature 411:834-842.

52. Wesley, S. V., Helliwell, C. A., Smith, N. A., Wang, M. B., Rouse, D. T., Liu, Q., Gooding, P. S., Singh, S. P., Abbott, D., Stoutjesdijk, P. A., Robinson, S. P., Gleave, A. P., Green, A. G., and Waterhouse, P. M. 2001. Construct design for efficient, effective and high-throughput gene silencing in plants. Plant J. 27:581-590. 